JFTH, Vol. 16, Issue 1 (2019)

ISSN: 2314-7024

E-ISSN: 2682-2180

\title{
Applying Gamification to Raise Awareness of Cultural Heritage in Egyptian Museums (Case Study: Alexandria National Museum)
}

\section{Iten Elrouby}

\author{
Assistant Professor- Tourism Department \\ Faculty of Tourism \& Hotels- Alexandria University
}

\section{Samar EI Kasrawy \\ Associate Professor- Tourism Department \\ Faculty of Tourism \& Hotels- Alexandria University}

\begin{abstract}
Gamification can be defined as the "use of game design elements in non-game contexts" (Deterding et al, 2011). Gamification is used to increase the motivation and engagement of users. It can be used in attracting and engaging tourists in all tourist activities, facilities and attractions. This study is concerned with using gamification in museums. This is due to the fact, that one of the main problems that face museums is that the displays are passive and non-engaging. During the last decade there have been several attempts to develop the concept of museums as being a static transmitter of history and cultural heritage into a dynamic, educational and entertaining institution.
\end{abstract}

The aim of the study is to investigate the possibilities to incorporate gamification approaches in Egyptian museums to raise awareness of cultural heritage. This has been achieved by using a quantitative research method. An online survey was designed and distributed among a purposive sample of young people to examine the effectiveness of gamification to raise awareness of cultural heritage in museums and enhance user's experience. The research hypotheses were tested using regression analysis, where the integration of gamified applications in museums was the independent variable while user engagement, education of cultural heritage and enhanced user experience were the dependent variables. In addition, a gamified application of a scavenger hunt in the Alexandria National Museum (ANM) was suggested in order to enhance user's experience and promote knowledge gain of visitors.

The results show that gamification is an effective tool to increase awareness of cultural heritage in museums. It also became clear, that gamification can be also used to provide the intended educational experience that has to be conveyed by museums combined with entertainment using emerging technologies to reach young people.

Keywords: Gamification, Cultural Heritage Awareness, Museums, Regression Analysis.

\subsection{Introduction}

The tourism industry is an experience based industry where information is said to be its lifeblood. This is explained by the fact that tourism products cannot be inspected before 
purchasing. Therefore, the travel industry was fundamentally altered by information technology; specially the internet.

Moreover, it has been proven that the tourism industry is more suited and influenced by new technologies than any other sector (Poon, 1993), where advances in ICTs (Information and Communication Technologies) has always played a major role in enhancing the tourism experience.

Gamification is a new trend in tourism that is used as a powerful tool in influencing consumer's motivation and behavior by creating a unique tourism experience (Xu et al 2013; Yılmaz and Coşkun, 2016). According to Zica et al. (2017), its concept is not a new one but it became more common since 2010.

The new tourist, also called the "digital" or "dot com" tourist, have completely different needs than the traditional ones. Thus, traditional tangible attractions like sea - sun sand are replaced by the need for experiences. Gamification apps can make tourists experience tourism destinations in many ways (Kovačević et al., 2014).

This study is an attempt to explore the use of Gamification in Egyptian Museums in order to retain its visitors, attract new ones, build an interactive relationship with them and finally, to raise their awareness of their cultural heritage for preserving it for future generations. The Alexandria National Museum was considered as a valuable case study where the possibilities of a gamification approach in Egyptian museums to raise awareness of cultural heritage can be incorporated.

More specifically to examine whether a gamified museum experience would:
1- improve knowledge gain of cultural heritage in comparison to a traditional museum experience?

2- enhance audiences' experience more than a normal museum?

3- increase user engagement in comparison to a traditional museum experience?

4- users be more motivated to see and learn more, and will they be more satisfied with the gamified museum?

5- enhance social interaction between players?

6- make the user spend more time at the museum?

7- encourage people to visit museums more often if there are gamification apps?

\subsection{Cultural Heritage and Museums}

"Cultural heritage consists of tangible and intangible, natural and cultural, movable and immovable assets inherited from the past. It is of extremely high value for the present and the future of a country. Access, preservation, and education around cultural heritage are essential for the evolution of people and their culture" ( http://www.ifla.org).

Cultural Heritage is of great importance for the tourism industry. Many studies have discussed the fact that cultural and heritage tourism is able to attract more tourists than any other type. As heritage tourists spend generously, it is expected that increased revenue can be brought to the community and country that host them as a mean to achieve economic benefits and sustainable tourism. Accordingly, it is of great importance to preserve the cultural heritage of any country (Ahmed, 2006). 
On the other hand, museums play a significant role in their communities with respect to culture, history, environment, social development as well as education. They are considered as important sites for families, tourists, school groups, cultural visitors and individuals, looking to enjoy, learn and expand their horizons.

According to ICOM (International Councils of Museums): "A museum is a non-profit, permanent institution in the service of society and its development, open to the public, which acquires, conserves, researches, communicates and exhibits the tangible and intangible heritage of humanity and its environment for the purposes of education, study and enjoyment" (http//: www.icom.museum). Hence, they are considered as the treasurers of cultural heritage.

Their role is not limited to just being window displays but being a lighthouse that guides local community and attracts them. Also, museums are responsible of raising awareness in their communities concerning cultural heritage preservation and tourism.

On the other hand, the growing concept of cultural heritage experience is demanding more interactive approaches. Recently, many efforts were committed in order to transform museum from their status as just being window displays into an interactive, educational and entertaining institution. One of the problems that face museums is that the displays are inactive and non-engaging.

However, museums who are taking advantage of the new developments in ICTs (Information and Communication Technologies) to their favor are of great success. ICTs can enable museums to establish a long term personal relationship with their visitors and attract new ones. They can offer interesting audience development programs with gamification online. Hence, they can make use of the global reach and personalized services.

For Example, the National Gallery London has developed an app for smart phones to maintain active relationships with their audiences allowing more collaborative and strong interactions. Apps and the mobile web can make museums and other cultural organizations take their artifacts beyond the walls and to position them within new social contexts with their audiences (Sexton and Lagoudi, 2016). Hence, Gamification can be used to increase the motivation and engagement of users.

\subsection{Gamification}

Gamification can be defined as the "use of game design elements in non-game contexts" (Deterding et al., 2011; Xu et al,2013; Kovačević et al 2014; Yilmaz \& Coşkun, 2016; Zica et al, 2017). Non-game context means that the game elements are used for reasons exceeding just playing and its main aim must be enhancing the user's experience (Yilmaz \& Coşkun, 2016). Similarly, Kovačević et al (2014) state that "Gamification is a marketing instrument used for developing client relationships, taking place in non-typical (nongame) and dynamical game environment".

Gamification can be used by Educators to help students to focus and become fast learners and by companies to improve employee productivity as well as customer loyalty and engagement and thus increase profitability (Yilmaz \& Coşkun, 2016). It can be used to provide more knowledge about products, services and destinations (Kovačević et al., 2014). 
Therefore, gamification can be used in the tourism sector to facilitate an interesting educational experience about a tourist destination (Sigala, 2015), its cultural heritage, attractions ...etc. At the same time, it can improve employee's performance and tourists' experience, loyalty and engagement and as a result increase tourist demand and revenue.

It can be used as an effective marketing tool for persuasion, motivation and manipulation that can help in increasing brand awareness and loyalty as well as effective marketing engagement (Kovačević et al, 2014; Sigala, 2015).

Moreover, gamification focuses mainly on rewards like adding points, levels, leader board and achievements, where the competition represents the best motivation in order to get involved in different activities (Zica et al 2017).

As a result, Gamification should mainly address two essential needs in any user; firstly, the need to interact and connect with other players within the same interest group and secondly, the need to feel being able in controlling the system and achieving goals. Consequently, games should be designed in a way that allows users to be recognized among peers by sharing same gamified system or related social systems. Also, goals should be divided into short-term achievable goals of flowing activities where difficulty arises gradually to enrich user's experiences (Xu et al, 2013b).

It is widely used in fields like health care, education and training, business but also in the service industry like tourism and hospitality (Sigala, 2015; Zica et al, 2017).

\subsection{Using Gamification in Tourism}

Gamfication has been used as a new marketing approach in tourism that is not only more target-oriented and cost, time and effort effective but is also way more creative than any other one (Yilmaz \& Coşkun, 2016). Moreover, this new marketing technique allows interaction from the tourist's side like no other.

According to $\mathrm{Xu}$ et al. (2013b) the application of game designed elements is already used in tourism but might not be recognized as the concept of gamification; e.g., frequent flying program's points are collected to be redeemed for a bonus.

Hence, applying the concept of loyalty programs in gamification, that has firstly been applied by airlines then followed by other tourism suppliers, can be a success for any destination, its attractions or tourism service providers.All this will lead to better understanding of the tourists' behavior patterns and decision process that can be successfully used to repeating behavior patterns and decision making.

Gamification should be carefully developed to meet each of the buying decision process as follows (Fig.1, adapted from Kim et al, 2009):

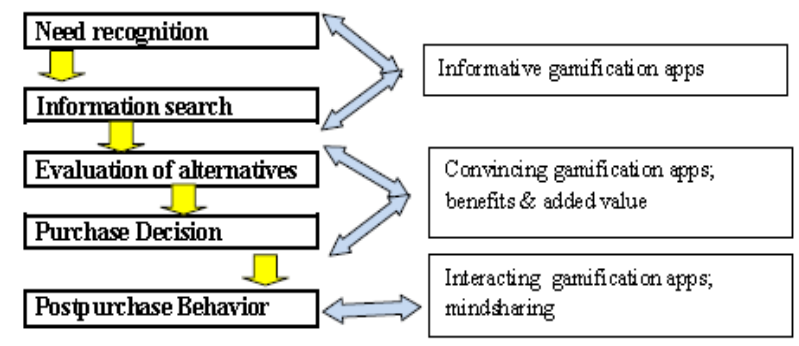

Figure 1: Gamification and the buying decision process

At the first and second stage of the buying decision process; need recognition and information search, the gamification app should be informative and designed in order to create awareness about the destination, 
attraction or service provider where the benefits of the amenities should be featured. However, at the third and fourth stage of the buying decision process; the gamification app should be convincing and designed in order to concentrate on the offerings compared to competitors where the benefits and added value from the purchase should be featured. At the final stage of the buying decision process; post purchase behavior, the gamification app should be designed in a way that encourages consumers to share their opinions about products and services where future purchase decisions can be achieved.

This complies with $\mathrm{Xu}$ et al's statement (2013a), that gamification tries to apply game design thinking in order to engage people into meaningful and effective activities. Accordingly, tourists are motivated to play a game for reasons like curiosity and wish to explore a destination or attraction and socializing for pre-travel, fun and fantasy experiences on site, challenge and achievement for post travel (Xu et al, 2013b).

Gamification goes along with the concept of relationship marketing that is widely used by the various tourism suppliers, especially airlines and hotels. Their main aim is to retain the loyalty of customers where loyalty programs schemes are used. They encourage using their services frequently to collect more points and be rewarded with free gifts and upgrades. The same can be applied in gamification where users can be awarded with free gifts and upgrades in case of achieving certain scores or share experiences and opinions. As for the tourists' point of view, they think that their cultural experience can be enhanced by combining mobile apps with gamification (Chen 2015).

More and more gamification is used in the tourism industry, for example, in Euro-
Disney, while waiting in queues, customers can get online and play games related to themes at the amusement park to pass time. In addition, many destinations use the gamified location-based marketing application of Foursquare, where customers can find and check-in in tourism attractions and firms in order to get special prices, share their location or experiences and invite others to join them. Also, Trip Advisor's fun-ware is developed to encourage travelers to use its website and to enhance the travelers' online experience and trip planning (Sigala, 2015). Other examples include:

- Trip-venture is an augmented reality mobile application that enables tourists to play a specific theme in Berlin, Hamburg, Cologne, Munich, Paris, London, Stockholm, Rome, and Barcelona.

- A Walk In My Shoes is designed to guide a tour in Sheakespeare's Stratford.

- Stockholm Sounds is a free gamebased augmented reality guide for visitors to Stockholm's best music and sound experiences offering rewards for good players.

- Drallo offers challenges designed for discovering new locations and landscapes in Switzerland including quizzes, treasure hunts to play, and score and win.

- TravelPlot Porto was designed to create a fun and engaging way to visit Porto's history, monuments, events , sights, and gastronomical delights while trying to locate a hidden treasure (Yilmaz \& Coşkun, 2016).

- Restaurants giving free dessert to game player's virtual game achievements such as Foursquare (Xu et al, 2013) and Mc Donalds 
- Turkish Airlines QR-coded national flags have been placed on 100 digital bus shelters for London 2012. Users who read the code can win a ticket to Australia

- Marriott My Hotel Aim of the social media game is to recruit new staff for job vacancies and familiarise players with various parts of a hotel (Xu et al, 2013b).

- The Serbia Convention Bureau (SCB) developed two video games; the first focuses more on the incentive products in Serbia and targets incentive planners as well as general tourists. The second video game targets meeting planners (Kovačević et al., 2014).

Other examples for using gamification in museums include "SS Great Britain" in Bristol, who wanted to develop a game that would teach visitors about Brunel's life and achievements. It was more dedicated to children to teach them about Brunel's work and learn from his mistakes. The children were able to build their own ship and they faced challenges like the ones' Brunel faced like crossing oceans and carrying heavy weights. They experienced adventures and discovered whether their designed ships are good enough to face the sea. They could also unlock particular content within the game. There was also a classroom version that teachers could utilize it in their classrooms as well. The children were interested to build the ships and learn from their mistakes (Blooloop, 2019)

"Gen" is another interactive online game developed in partnership with The National Museum of Scotland and funded by the Wellcome Trust. The museum was trying to throw light on biomedical science by developing a character called Gen. Players care for him using real objects from the museum's collections. As Biomedical science is hard to understand, the game makes it more fun to reach a broader audience (Blooloop, 2019).

The respondents were asked to rate certain factors related to museum visits like "Location/ease of getting to the museum", "Audio guides", "Cooperation of Museum staff/volunteers", Value For Admission Price and "Public programs". They considered aspects like "Virtual Reality apps", "Exhibitions", "Museum Shops", "Family/Children's educational programs" and "Gamification apps" as important. This result assures the more and more increasing importance of gamification usage.

As a result, gamification can be used in the tourism industry in order to increase brand awareness and enhance its image (whether destination, attraction, service provider, tourism products or services), as well as to attract potential customers. It can also be used in order to encourage interaction and hence enhance tourist experiences (Xu et al. 2013b).

\section{Research Methodology}

In order to test the research hypotheses, the researchers used a multi-faceted research method.

\section{First stage:}

- The researchers conducted an online survey to examine the influence of gamification applications in museums on user engagement and education of cultural heritage.

- A quantitative method of data gathering was used with a sample space of 456 candidates with age range between 18 and 45. This purposive sampling method was chosen because 
this age range is the one mostly involved in gamification applications.

- The survey was divided into three parts. The first part gathered demographic data. The second part was examining museum visiting habits and was concerned about the future of traditional museums. Furthermore, it rated services offered at the museum. The third part examined the influence of gamification applications on respondents in general and the establishment of gamified applications in museums in particular.

\section{Second stage:}

These hypotheses were tested using regression analysis, where the integration of gamified applications in museums were the independent variable and user engagement, education of cultural heritage and enhanced user experience were the independent variables.

\section{Third Stage:}

A gamified app of a scavenger game in the Alexandria National Museum (ANM) was suggested in order to enhance user's experience.

\subsection{Research method}

This research can be categorized as descriptive- analytical. In order to test the research hypotheses, the researchers used a quantitative research method. A purposive sampling method was chosen as a data collection technique. According to this technique, which belongs to the category of non-probability sampling techniques, sample elements were chosen on the basis of their knowledge, relationships and expertise regarding a research subject (Freedman et al., 2007). In the current research, the sample members who were selected had special knowledge and background with the phenomenon under investigation, experience in the field of information technology and active involvement in approaches related to new applications.

Several studies indicated that the selected age range is the one mostly involved in gamification applications and is a dynamic applicant for information technology use. These studies state that "Generation Z" (teenagers specifically) are submerged in modern technologies and are massively engaged with platforms for information sharing (Napoli and Ewing, 2000).

The research tended to test the hypotheses, which were as follows:

$\mathrm{H}_{1}$ : A gamified museum experience will improve knowledge gain of cultural heritage in comparison to a traditional museum experience.

$\mathrm{H}_{2}$ : A gamified museum will enhance audiences' experience more than a traditional museum.

$\boldsymbol{H}_{3}: A$ gamified museum experience will increase user engagement in comparison to a traditional museum experience.

\subsection{Data review and analysis:}

The first group of questions gathered personal data. $82.6 \%$ of the respondents were females while $17.4 \%$ were males. The results of the question which involved "Highest education level completed" indicated that $76.5 \%$ held a high school degree, $14.8 \%$ held a bachelor degree while $8.7 \%$ were post graduate students. Concerning age range, the majority ranged between 18 to 25 years old $(83.5 \%)$, followed by age range 31 to $40(9.6 \%)$.

The results showed that most respondents were interested in natural history museums (57\%) followed by art museums (24.2\%). 
When asked about the major problems facing museums in the next years, most of the respondents strongly agreed that it was "limited financial resources", "deterioration of assets" and "people losing interest in visiting museums".

The respondents were also asked to rate the major strengths of museums (Fig. 2). The majority agreed that its major strength was "Help future generations comprehend their history" by $(73.2 \%)$, "Strengthening Cultural heritage knowledge" by $(72.5 \%)$ and "Educational purposes" by (36.9\%), respectively. Factors like "Social interaction when museums engage in cultural community events" and "Entertainment" weren't greatly valued by the respondents $(16.1 \%, 8.7 \%$ successively).

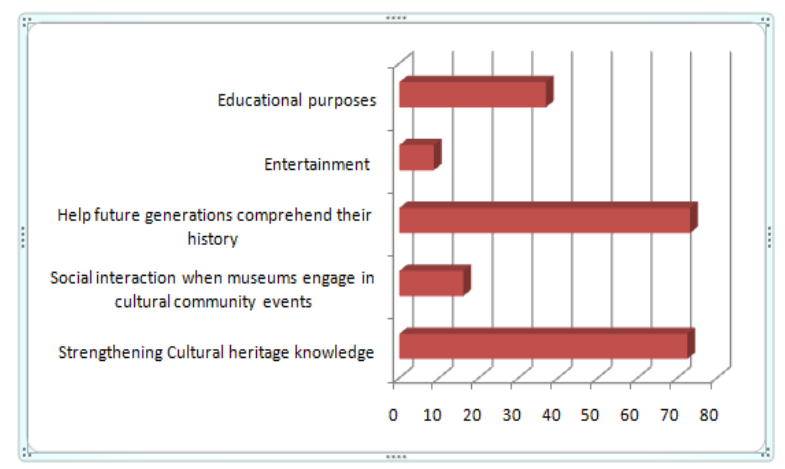

Figure 2: Major strength of museums

The respondents were asked to rate which membership benefit they valued the most. Results indicated that "Reduced fees for education programs" were the most valued by $54.1 \%$, followed by "Reduced admission to other museums" (52\%), "Complimentary admission" (30.4\%) and "Subscription to Museum newsletter" (27.7\%), respectively.

Most of the respondents visited the museums 2 to 3 times, $26 \%$ visited museums once and $16 \%$ visited them 4 to 6 times. This shows that museums need to be more attractive to prospective visitors. They should introduce new applications to draw user's attention to cultural heritage.

The primary reasons for visiting museums according to the respondents were "To see exhibitions" (43\%), "Just looking for something to do" (17\%), "Family or friend recommended it" (16\%) and "Information on social media" (16\%), respectively, (Fig.3).

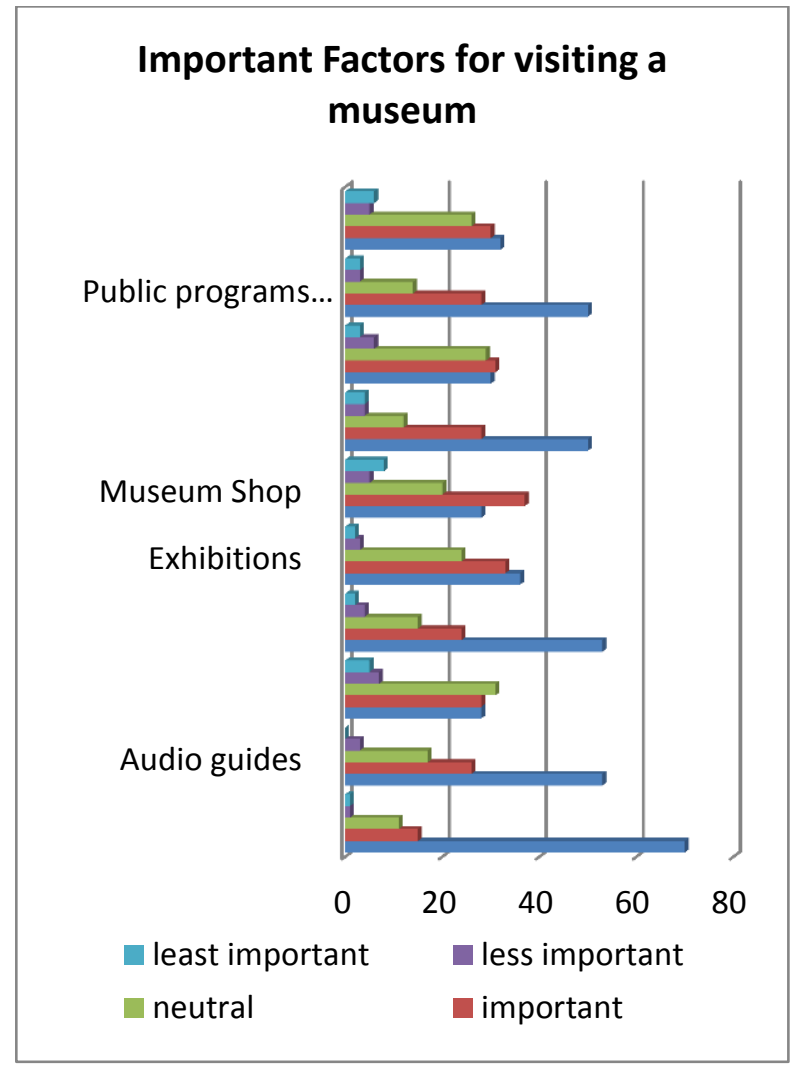

Figure 3: Important reasons for visiting museums

The respondents were asked to rate certain factors related to museum visits, where "1" indicated very important and "5" stood for least important. The median of factors "Location/ease of getting to the museum", "Audio guides", "Cooperation of Museum staff/volunteers", Value For Admission Price and "Public programs" was " 1 " which stands for very important. The median value for aspects such as "Virtual Reality apps", "Exhibitions", "Museum Shops", "Family/Children's educational programs" and 
"Gamification apps" was " 2 " which indicated important. The mean values for the same aspects related to museum visits lay between 1.45 and 2.3 which indicates that the majority of the respondents rated these aspects between "very important" and "important". These results indicate that museum managers should increase the efficiency of the services offered in museums in order to guarantee a successful experience for their visitors.

The following cluster of questions was directed to Information Technology (IT) application. The respondents were asked to mention on an average day, how many hours they usually spend in playing video games recreationally (on mobile phones, computers, etc.). The majority of the respondents indicated that they spend zero to one hour on technological devices per day (34\%). Another group pointed out that they spend two to three hours per day (22.4\%) playing video games while approximately $13 \%$ explained that they spend more than five hours per day doing the same.

The respondents were asked what elements they preferred to see in games. $54.5 \%$ indicated that they preferred "reward elements", followed by "competitive elements" (43.4\%) and social elements $(34.5 \%)$ respectively. Furthermore, they were also requested to state the type of games they preferred to play. $42 \%$ pointed out that they preferred "puzzle games" while 52\% explained that they liked "adventure games" (42\%). 22\% indicated that they liked "role playing" and 20\% favored "strategy games".

The next group of questions was concerned with the respondents' opinion concerning the effect of gamification on enhancing "knowledge of cultural heritage", "audiences' experience", "user engagement", "motivation and satisfaction", "social interaction between visitors", "times spent at the museum" and "more visits to museums".

The opinions were rated on a likert scale were "1" stood for strongly agree and "5" represented strongly disagree. The mean of the answers of enhancing "knowledge of cultural heritage", "audiences' experience", "user engagement", "times spent at the museum" and "more visits to museums" was 1.9 while the mean of the factor enhancing "social interaction between visitors" was 2.1. The answers of factor "motivation and satisfaction"

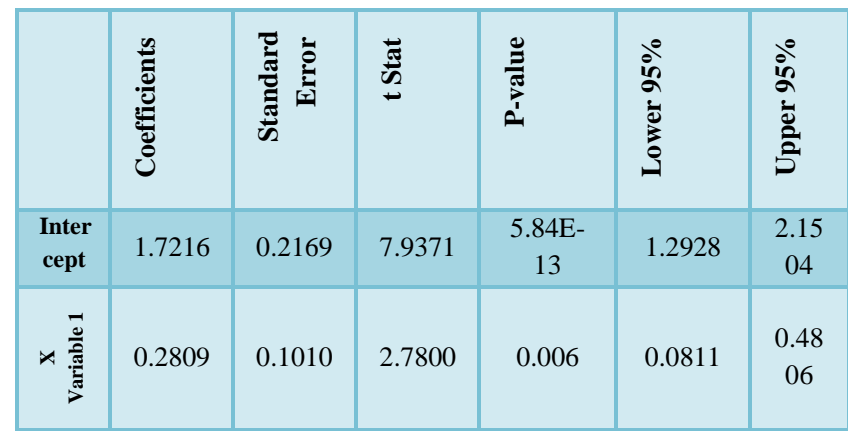

had a mean of 1.7. The median of all the answers of all factors was 2 . These results indicate that the respondents considered gamification application an important factor to enhance user engagement, knowledge and experience.

\subsection{Linear Regression analysis and Hypothesis Testing}

A regression analysis was conducted to test the hypotheses of the research. Regression analysis tends to examine the influence of independent variables on a dependent variable. The dependent variables in this research were knowledge gain, visitors experience and user engagement.

- The first hypothesis stated:

H1: A gamified museum experience will improve knowledge gain of cultural heritage. 
Table 1: Regression analysis of variables gamified applications and knowledge gain

\begin{tabular}{|c|c|c|c|c|c|c|}
\hline & Uू. & 总 & 苛 & & 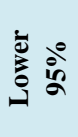 & 產 \\
\hline 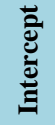 & 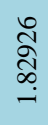 & 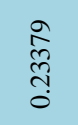 & 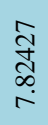 & $\frac{\mathfrak{T}}{\text { t't }}$ & $\begin{array}{l}\hat{2} \\
\text { b } \\
\text { ?. }\end{array}$ & 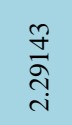 \\
\hline$\frac{\dot{\vec{\sigma}}}{\stackrel{\vec{\pi}}{\pi}}$ & 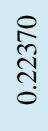 & $\begin{array}{l}\hat{n} \\
\hat{o} \\
0\end{array}$ & $\begin{array}{l}\stackrel{8}{0} \\
\underset{+}{0} \\
i\end{array}$ & 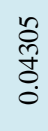 & 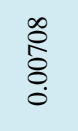 & 周 \\
\hline
\end{tabular}

The coefficient for knowledge gain is 0.223 . The coefficient value signifies how much the mean of the dependent variable changes given a one-unit shift in the independent variable while holding other variables in the model constant. So an increase in gamification appliances, would lead to an increase in knowledge of cultural heritage, holding all other variables constant. The value of $p$ is significant $<0.05$ (Table 1).

- The second hypothesis stated:

H2: A gamified museum will enhance visitors' experience

Table 2: Regression analysis of variables gamified experience and visitors' expereince

The coefficient for enhancement of user experience is 0.2809 . So for an increase in gamification appliances, an increase in visitors experience is predicted, holding all other variables constant (Table 2).

The p-value for each term tests the null hypothesis that the coefficient is equal to zero (no effect). A low p-value $(<0.05)$ explains that the null hypothesis is rejected. In other words, a predictor that has a low p-value means that changes in the predictor's value are associated to changes in the response variable.
The value of $p$ in this case is significant at (0.0061).

- The third hypothesis stated:

H3: A gamified museum experience will increase user engagement in comparison to a traditional museum experience.

Table 3: Regression analysis of variables gamified experience and user engagement.

\begin{tabular}{|c|c|c|c|c|c|c|}
\hline & Uُّ & 壳 & $\underset{\omega}{\tilde{\omega}}$ & 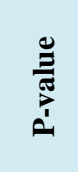 & $\begin{array}{l}0 \\
10 \\
\alpha \\
\vdots \\
0 \\
0 \\
0\end{array}$ & 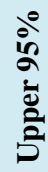 \\
\hline Intercept & $\begin{array}{l}\text { \& } \\
\infty \\
0 \\
0\end{array}$ & 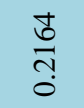 & 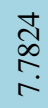 & $\stackrel{\substack{1 \\
\infty}}{\stackrel{-}{-}}$ & $\begin{array}{l}\hat{\circ} \\
\\
\end{array}$ & $\begin{array}{l}\stackrel{2}{I} \\
= \\
\text { i }\end{array}$ \\
\hline $\begin{array}{c}\mathbf{X} \\
\text { Variab. }\end{array}$ & 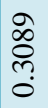 & $\begin{array}{l}\infty \\
\stackrel{0}{0} \\
0\end{array}$ & $\hat{\hat{n}}$ & 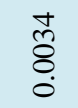 & $\begin{array}{l}n \\
\tilde{o} \\
0\end{array}$ & $\frac{\mathfrak{I}}{\tilde{f}}$ \\
\hline
\end{tabular}

The coefficient for enhancement of user engagement is 0.3089 (Table 3). So an increase in gamification appliances, would lead to an increase in user engagement, holding all other variables constant. The value of $p$ is significant at (0.0034).

Thus hypothesis 1, 2 and 3 can be accepted substantiated by the results of regression analysis.

\subsection{Discussion of results}

The sample of the research was a purposive sample of college students with mostly an age range between 18-25 years. "The postmillennial Generation $\mathrm{Z}$ are variously defined as "those people born between the mid-1990s to the early 2010 s and therefore can be aged ranging from 7 to 22 years old today in 2017 " (Tapscott, 2009).

As previously mentioned, this age range is mostly involved in new technologies. According to Skinner et al. (2018), “...... with 
Millennials and Generation $\mathrm{Z}$ also being those that seek adventure, and gamified experiences involving riddle solving and overcoming physical challenges .....”.

The results showed that most respondents were interested in natural history museums followed by art museums. These results may dictate policies that should be heading to put more support to these types of museums. moreover, these results show that more effort should be made in order to attract more visitors to cultural heritage museums.

The respondents stated that the major problems that will be facing museums in the next years were "limited financial resources", "deterioration of assets" and "people losing interest in visiting museums". Therefore, governments and non-profit organizations that are interested in promoting cultural heritage should be focusing on activities that could attract visitors to visiting museums. Gamification, virtual reality and augmented reality technologies are emerging tools that could attract a wide range of museum visitors.

The respondents were asked to rate the major strengths of museums. $73 \%$ stated that museums' major strength was to "Help future generations comprehend their history" followed by "Strengthening Cultural heritage knowledge" followed by "Educational purposes" successively. The role of museums consists of educating the public about culture and history and preserving cultural heritage. But this role has always been hard for curators to achieve in an appealing and interesting way in addition to engaging users. Nowadays, with the emergence of new technologies, it is easier to attract visitor's interests, interact and engage them by offering all kind of information using these technologies that make it more interesting.
The respondents were asked to rate which membership benefit they valued the most. They indicated that "Reduced fees for education programs" were the most valued followed by "Reduced admission to other museums", "Complimentary admission" and "Subscription to Museum newsletter". Accordingly, the previously valued benefits can be used as rewards for completing each level in a game.

Most of the respondents visited the museums 2 to 3 times, $26 \%$ visited museums once and $16 \%$ visited them 4 to 6 times. This shows that museums need to be more attractive to prospective visitors. They should introduce new applications to draw user's attention to cultural heritage.

The primary reasons for visiting museums according to the respondents were "To see exhibitions", "Just looking for something to do", "Family or friend recommended it" and "Information on social media", respectively; Museums should engage visitors in interesting activities in order to enhance the numbers of visitors. Activities should be also continuous to ensure visitors' retention like offering gamification applications in the museums that require several visits to the museum to complete the levels and that encompass free giveaways if they finish the game. The notion of museums as being an unexciting place that transmits rigid data should be changed by curators and more amusement should be included in the activities. More digital interactive initiatives should be taken into consideration to ensure visitors' retention. Museums should provide people with the right tools and knowledge to develop a personal connection with the objects they are watching. Several projects have been initiated to use 
gamification in museums to create this interrelation between exhibits and visitors.

The following group of questions focused on Information Technology (IT) applications. The respondents were asked the average time they spent in playing video games on mobile phones or computers. The majority of the respondents indicated that they spend zero to one hour on technological devices per day (34\%) while another group stated that they spend two to three hours per day $(22.4 \%)$ and approximately $13 \%$ explained that they spend more than five hours per day. This shows that playing video games is becoming a daily routine by the majority of respondents. This can be an insinuation to museum policy makers that intend to attract visitors by incorporating interactive games in museums to educate and engage users and enhance their experience.

The respondents explained that they preferred to find reward elements, competitive elements and social elements integrated in games. Furthermore, they stated that they preferred to play puzzle games, adventure games, role playing and others favored strategy games. These preferences should be also considered by developers when designing museum games.

The next group of questions was concerned with the respondents' opinion concerning the effect of gamification on enhancing "knowledge of cultural heritage", "audiences' experience" ...etc. The answers of enhancing "knowledge of cultural heritage", "audiences' experience", "user engagement", "times spent at the museum" and "more visits to museums" indicated that the respondents considered gamification application an important factor to enhance user engagement, knowledge and experience.

\subsubsection{Alexandria National Museum:}

Based on the results of the online survey, which indicated that gamified applications are considered an interesting option to increase user experience, knowledge gain and user engagement, a framework was suggested for Alexandria National Museum to implement a gamified application "Treasure Hunt" in the museum using the precious in-door exhibitions. This application is intended to enhance user engagement, increase knowledge about cultural heritage, enhance social interaction between players and ensure an amusing experience for museum visitors.

The Alexandria National Museum was opened to the public in 2002 . It covers a total area of 3,480 square meters and is built in the style of an Italian Mansion with four large floors. It contains more than 1800 pieces from different civilizations (Pharaonic, Greco-Roman, Byzantine, and Islamic). The museum gives an inclusive picture of not only Alexandrian history but an overview of the whole history of Egypt.

The first floor of the museum includes the Pharaonic items including a lot of statues of different ancient Egyptian gods and leaders and very attractive portraits of Menkaure, Ikhnaton, and Hatshepsut. Mummies are also displayed to the public in secret underground chambers.

The middle floor of the museum includes the antiquities of the Greco-Roman period. There are various statues of Greek ladies and a statue of the god Serapis, as well as a granite statue of Caracalla.

The last floor of the museum displays items belonging to the Coptic and Islamic civilizations. There are also some interesting icons that demonstrate religious scenes of 
Christ and the Last Supper. The collection consists of 162 Islamic coins, candle holders, and a variety of other items. There is also the section of the royal family of Mohamed Ali that includes a lot of jewelry pieces.

The most interesting section in the museum is the section that displays antiquities that were discovered during the underwater excavations in Alexandria. The museum also displays live pictures of how these items were pulled out of the sea. This section displays an interesting statue of the head of Alexander the Great among other items.

A hall in the cellar of the museum has been converted into an audio-visual workshop. Here visitors can tour the museum via computer programs that show each item from a variety of angles (ask-aladdin, 2019; memphistours, 2019; touregypt, 2019).

The suggested gamified application for the Alexandria National Museum is explained below.

\subsubsection{Scavenger Hunt Game design:}

The game is about a thief who tries to steel some treasures from the museum. After he steels the articrafts, he splits them and hides them in the museum. He was caught by the police and during the interrogation he gives some clues about the hidden treasures. The player, who is the policeman, tries to find out which piece of treasure the thief is talking about and where it is hidden in the museum. As the national museum consists of different floors and different periods, it will be a challenge to identify the intended treasure. The game consists of different levels. Every level is associated with a floor which represents a certain period in the Alexandria National Museum. When the player finishes a level and is promoted to the higher level, he is transferred to a different period.

Here the players are going to learn through gamification information about the articrafts of the museum; they will also communicate with other players through synchronous channels like social media to help each other and will be rewarded whenever they solve a riddle by being elevated to the next level. The museum can also offer free tickets to the activities of the museum if the players found all of the stolen articrafts. There may be also credit points for helping other players and these credit points may be used to give an extra clue.

Several studies have shown the good effect of family members engaging in a collaborative group play. These researches indicated that interfaces that do not involve group social interaction and participation are one of the key reasons technologies don't succeed in museum settings (Pujol-Tost, 2011).

\section{Conclusion and Recommendations}

Egyptian museums have a very important role in not just being window displays for the treasures of Egyptian cultural heritage but mainly to raise awareness of them in order to be preserved for future generations. Consequently, they should be able to attract more visitors, retain their loyalty and build an interactive relationship with their audience and eventually enhance their users' experience. Therefore, they should focus on innovative strategies to attract visitors specially young ones.

This can be achieved by using the new developments of ICTs to their favor, especially augmented reality, virtual reality, QR codes and above all gamification. Hence, transmitting cultural heritage to new 
generations can be made fun through gamified applications

This is especially true as museums are regarded as ideal environments to experiment informal learning technologies (Pierroux et al., 2007). Several studies showed that games intended for museum learning frequently involve the use of mobile devices, with missions like treasure hunting and mystery solving (Cabrera et al., 2005; Dini et al., 2007) or activities that entail students' problemsolving involving school and museum contexts (Pierroux et al., 2011; Charitonos et al., 2012; Bakken and Pierroux, 2015).

Therefore, gamification can be used as an effective tool to increase awareness of cultural heritage in Egyptian museums. It can be used to provide the intended educational experience that has to be conveyed by museums combined with entertainment using emerging technologies to reach young people. Museum experience should be transformed to a gaming experience.

These gamified applications should be used in museums in association with virtual reality to ensure optimal results and be made simple and user-friendly. Players should be able to communicate with each other, either through social networks or sharing same gamified system. Game leaders can influence other travelers' perceptions and their behavior. Thus, the technologies used should be compatible with all kinds of mobile phones.

Moreover, players should be motivated to overcome challenges that get more difficult gradually and be rewarded each time they finish one level and are upgraded to the next one. Bonus points should therefore be linked with the games (e.g. free tickets to the museum) to encourage visitors. However, the games should not overshadow the concept of transmitting cultural heritage.

In addition, collaboration between Egyptian museums should take place to be able to link the museums in a network for mutual benefits. For example, a gamified application could include several museums and rewards can be extended to get free tickets to other national museums. The same can be applied also with international museums, especially those who have Egyptian collections in their displays, like Berlin Museum, The British Museum, the Louvre Museum, the Metropolitan Museum...etc. this will not only raise awareness of Egyptian cultural heritage on the national level but also worldwide and as a result attract international visitors and enhance their tourist experience.

The above mentioned recommendations can also be addressed to destination managers in order to use gamification to help travelers colearn the destination, influence traveler's perception of the destination and also its image and finally make them take the buying decision to visit their destination and enhance their visiting experience and influence their post purchase behavior. This can certainly be extended to other attraction managers and all kinds of service providers.

\section{References}

1. Ahmed A.G. (2006), Cultural Heritage of Southeast Asia: Preservation for World Recognition, Journal of Malaysian Town Plan, Vol. 03, No. 1, January 2006, pp. 52-62.

2. Alexander, E.P \& M. (2008), Museum in Motion : An Introduction to the History and Functions of Museums, Rowann \& Littlefield.

3. Ask-aladdin (2019), Available at : https://www.ask-aladdin.com/alex-travelinformation/alexandria-national-museum/. Accessed February 2019.

4. Bakken, S. M., \& Pierroux, P. (2015). "Framing a Topic: Mobile video tasks in 
museum learning. Learning ", Culture and Social Interaction, Vol.(5), pp.54-65.

5. Blooloop (2019). Available at: https://blooloop.com/features/gamificationmuseums-aardman-amnh/. Accessed February 2019.

6. Cabrera, J. S., Mu, H., Frutos, H.M., Stoica, A. G., Avouris, N., . . . Liveri, K. D. (2005). "Mystery in the museum: collaborative learning activities using handheld devices". Proceedings of the 7th International Conference on Human Computer Interaction with Mobile Devices \& Services, Salzburg, Austria.

7. Charitonos, K., Blake, C., Scanlon, E., \& Jones, A. (2012). Museum learning via social and mobile technologies: (How) can online interactions enhance the

8. visitor experience? British Journal of Educational Technology, Vol. 43(5), pp. 802819.

9. Deterding, S., Dixon, D., Khaled, R., \& Nacke, L. E. (2011). From game design elements to gamefulness: Defining gamification. Mindtrek 2011 Proceedings. Tampere, Finland: ACM Press.

10. Dini, R., Paternò, F., \& Santoro, C. (2007). "An environment to support multi-user interaction and cooperation for improving museum visits through games “. Proceedings of the 7th International Conference on Human Computer Interaction with Mobile Devices \& Services, Singapore.

11. Freedman, D.; Pisani, R. and Purves, R. (2007), Statistics. Fourth edition, W.W Norton \&Company, Inc.

12. Humphreys, A. and Eyewitness, DK(2011), Top 10 Cairo \& The Nile, Penguin, pp. 113, Sep. 2011.

13. Kovačević, I., Zečević. B and Veljković, S. (2014), Gamification Concept: Theoretcal Framework and Destination Marketing Management Practice, EKONOMIKA PREDUZEĆA, Serbia, pp315-322.

14. Memphistours (2019), Available at: https://www.memphistours.com/Egypt/WikiTr avel/Attractions Alexandria/wiki/AlexandriaNational-Museum. Accessed February 2019.

15. Napoli, J., Ewing, M.T. (2000). The Net Generation. J. Int. Consum. Mark. Vol. (13), pp. 21-34 (2000).

16. Nicholson, S. (2015), A Recipe for Meaningful Gamification, In Reiners,T. and Wood, L.C.,
Gamification in Education and Business, Switaerland: Springer International Publishing 2015.

17. Pujol-Tost, L. (2011). Integrating ICT in exhibitions. Museum Management and Curatorship, Vol. 26 (1), pp.63-79.

18. Pierroux, P., Bannon, L., Kaptelinin, V., Walker, K., Hall, T., \& Stuedahl, D. (2007). "MUSTEL: Framing the Design of Technology-Enhanced Learning Activities for Museum Visitors”. International Cultural Heritage Informatics Meeting Proceedings (ICHIM), Toronto.

19. Pierroux, P., Krange, I., \& Sem, I. (2011). Bridging Contexts and Interpretations: Mobile Blogging on Art Museum Field Trips. Mediekultur. Journal of Media and Communication Research, Vol. 50, 25-44.

20. Poon, A. (1993), "Tourism Technology and Competitive Strategies", UK, CAB International.

21. Richardson, D. and Jacobs, D. (2011), The Rough Guide to Cairo \& the Pyramids, Penguin, pp. 248, Sep.2011.

22. Sexton C. and Lagoudi E.(2016), Museum Apps and Audiences on the Go., Museum Identity Ltd.

23. Sigala, M. (2015), The application and impact of gamification funware on trip planning and experiences: the case of TripAdvisor's funware, Electron Markets (2015) 25:189-209.

24. Skinner, H.; Sarpong, D. and R.T. White, G. (2018) "Meeting the needs of the Millennials and Generation Z: gamification in tourism through geocaching", Journal of Tourism Futures, https://doi.org/10.1108/JTF-12-2017$\underline{0060}$

25. Tapscott, D. (2009), Growing Up Digital: How the Net Generation is Changing Your World, McGraw-Hill, New York, NY.

26. The International Council of Museums (ICOM), available at http://icom.museum Accessed November 2018.

27. The International Federation of Library Associations and Institutions (IFLA), available at: http://www.ifla.org, accessed 15 November 2017.

28. Touregypt (2019), Available at: http://www.touregypt.net/featurestories/alexan drianationalmuseum.htm. Accessed February 2019.

29. Wikia: Generation Z: a Look at the Technology and Media Habits of Today's 
Teens. Available at:

http://www.prnewswire.com/news-

releases/generation-z-a-look-at-the-technologyand-mediahabits-of-todays-teens-

198958011.html. Accessed January 2019.

30. Xu F, Tian F, Buhalis D (2013a) Marketing tourism via electronic games: understanding the motivation of tourist players. In: 5th international conference on games and virtual worlds for serious applications (VS-GAMES), Institute of Electrical and Electronic Engineers, Inc. Bournemouth, 11-13 Sept 2013

31. Xu, F., Weber, J. and Buhalis,D. (2013b) Gamification in Tourism,In Z. Xiang and I. Tussyadiah (eds.), Information and Communication Technologies in Tourism 2014, DOI: 10.1007/978-3-319-03973-2_38, Springer International Publishing, Switzerland 2013

32. Yılmaz, H. and Coşkun, I(2016), New Toy of Marketing Communication in Tourism: Gamification, In: e-Consumers in the Era of New Tourism 2016, Springer, Turkey, pp53-72

33. Zica, M., Riurean, S., Ionica, A. and Leba, M. (2017), Gamification in Tourism Mobile Application Development, International Journal of Tourism, Vol. (2), http://www.iaras.org/iaras/journals/businesseconomics/ijt 